\title{
Murray Sidman: The Accidental Philosopher
}

\author{
Bryan Roche \\ National University of Ireland, Maynooth
}

I have always thought of Sidman's classic text, known affectionately as Tactics (1960), as primarily a philosophy of science text. I was surprised to learn that Sidman himself did not see it as particularly relevant to the philosophy of science (Sidman 2011, this volume). It appears that since 1960 Sidman has been busy doing his ground-breaking basic and applied work unaware of his status as a philosopher of science, at least to some of us. This is surprising, because on reading the Remarks series, it is apparent that Sidman does not reside at the centre of our science, but at the very edge. No good behavioral engineer can push the boundaries of their own discipline, as Sidman has done, without a keen appreciation of the philosophy of their science.

Contained within Sidman's Remarks are superb illustrations of the radical behaviorist's approach to behavior. These illustrations draw upon a nuanced appreciation of our basic units of analysis that one rarely encounters in daily practice. However, there is a consistent and important theme running through these papers regarding the inferential nature of behavioral units. On several occasions, explicitly and implicitly, Sidman raises the crucial matter of stimulus control as an inference (e.g., Sidman, 1977a). Indeed, there is nothing in the behavioristic formulation that requires behavioral units to be anything more tangible than an inference. $\mathrm{He}$ argues that unless we accept that stimulus control is an inference (a discrimination of the effectiveness of our own experimental manipulations across time), we may be seduced into seeking mediational accounts

This article is concurrently published in the jorunal Behavior and Philosophy.

Address for Correspondence: Bryan.T.Roche@nuim.ie to explain stimulus-stimulus relations (e.g., such as stimulus equivalence). Seeking a mediational account is surplus to requirements and Sidman clearly sees that seeking one will hamstring the development of stimulus control based accounts of cognition, in which he shows a keen interest. Sidman summarized the idea as follows;

... we can never see a controlling relation, with surety. We can only infer its existence actuarially and post hoc after a number of instances have permitted us to rule out other controlling relations (emphasis in original; 1977a, p 280).

Sidman speaks loosely of stimuli and responses in other passages, suggesting that perhaps these particular behavioral units are in fact not inferences. For example in one passage he says;

We can, of course, observe and measure a single instance of any stimulus, but we can never know except by inference whether we are actually observing a particular controlling relational between two stimuli or between a stimulus and response. Unlike individual stimuli and responses, controlling relations are not directly observable (1979, p. 123).

However, this would appear to be language of convenience. Stimuli and responses are, of course, themselves classes that must be discriminated across multiple observations. In other words, they too must be inferred (i.e., they are functional units). While instances of a stimulus may be observable, the stimulus itself is not (i.e., it is a class). In another passage from the Remarks series Sidman clarifies the foregoing issue while discussing the foundational co-definition of stimuli and responses.

If neither stimulus nor response can be defined except circularly, each by reference to the other, 
then neither of them alone can constitute our fundamental unit. The unit must include both. Behavior is not to be equated only with responses, but must include the relation of responses to controlling stimuli (1978 p. 266; see also Skinner, 1938, p. 9).

This final statement is profoundly important, and leads to the conclusion that behavior may not the observable activity of organisms (what many of us may loosely think of as "responses"). This radical implication that I am inferring from Sidman's remarks are perhaps best summarized by his observations of the location of behavior.

Perhaps the learner's performance is not the critical datum at all. For example, if the occurrence or nonoccurrence of errors merely specifies a relation between the behavior of the learner and the teacher, perhaps theories of learning should stress the behavior of teachers rather than of learners" (emphasis in original; 1977a, p 112-113).

The point is made again in his 1979 paper.

Learning curves might just as well be called teaching curves, for they allow us to infer at least as much about the behavior of experimenters as about the behavior of subjects (1979, p. 125).

These comment leave us in no doubt that behavioral units are not to be bound by the observable activity of our subjects. They are spatio-temporally extended units based on inference made across time (see also Hull, 1984; Roche \& Barnes, 1997).

While a distinction between behavior and organismic activity may seem unintuitive, it is in fact crucial if we are to competently address the matter of complex forms of derived relational responding, which patently involves overarching classes of responses, defined non-topographically, but rather relationally. Based on our community's former reluctance to entertain the concept of stimulus-stimulus relations in the absence of mediation, and some current resistance to the possibility of more complex stimulusstimulus relations, such as complex derived relational responding (i.e., relational frames), it would appear that many of us do not in practice appreciate the spatio-temporally extended nature of operant units and the inferential nature of stimulus control. Sidman's insights bring us face-to-face with the profoundly simply, but infinitely expansive and abstracted nature of our behavioral units. Behavioral units incorporate instances, but they are not them.

Sidman expressly raised these issues in the context of arguing for the need for stimulus control analyses of cognitive phenomena. But I wonder if he appreciates that once the break has been made between functional behavioral units and the discrete topographies of organismic movement that participate in those units, there is no end to the forms of complex behavior that can be brought into our remit as experimental analysts of behavior. The remit is much broader than stimulus-stimulus relations defined in terms of functional equivalence or mutual substitutability (i.e., stimulus equivalence). Once the operant and its constituent parts have been freed from the constraints of observable discrete activities, the operant expands spatio-temporally to infinity. That is, if mediation is not required to validate stimulus control measures, and if response classes are not defined by topography, then any pattern of response forms that is functionally related to any pattern of stimulus forms constitutes a stimulus-response relation. Similarly, any pattern of stimulusstimulus relation, whether it is takes the form of functional equivalence or not, can constitute a legitimate basis for stimulus control. For instance, the observation that a subject can always choose from a range of comparison stimuli, the one that is "greater than" a sample stimulus, requires no mediational account, and the novelty of the stimulus forms employed in such a test does not pose a threat to the integrity of an account based on generalized relational responding in accordance with a "comparative relation" (i.e., the language of Relational Frame Theory; Hayes, Barnes-Holmes, \& Roche, 2001). 
Sidman may not have until recently thought of his Tactics as relevant to the philosophy of science. It seems to me that he was amongst the last to know! To me Sidman was always a Philosopher; literally a lover of knowledge. He has also been mentor-at-a-distance to countless numbers of us attempting to practice and improve our science. But I am heartened that Sidman has finally voiced his interest in philosophical matters, and reminded our community of behavioral engineers that not all questions are empirical ones.

\section{References}

Hayes, S. C., Barnes-Holmes, D. \& Roche, B. (Eds.), (2001). Relational frame theory:
A post-Skinnerian account of human language and cognition. New York: Plenum Press.

Hull, D. L. (1984). Units of evolution: A metaphysical essay. In R. N. Brandon \& R. M. Burian (Eds.), Genes, organisms, populations: Controversies over the units of selection (pp. 142-160). Cambridge, MA: MIT Press.

Roche, B. \& Barnes, D. (1997). The behavior of organisms? The Psychological Record, 47, 597-618.

Sidman, M. (1960). Tactics of scientific research: Evaluating experimental data in psychology. New York: basic books.

Skinner, B. F. (1938). The behavior of organisms. Englewood Cliffs, NJ: PrenticeHall. 